\title{
NILAI TEOLOGI DALAM GURINDAM DUA BELAS RAJA ALI HAJI
}

\author{
Nurliana \\ Pendidikan Agama Islam STAI Diniyah Pekanbaru Riau \\ e-mail: nurlianamalay@gmail.com
}

\begin{abstract}
Abstrak: Kalimat yang baik ialah kalimat tauhid, segala ucapan yang menyeru kepada kebajikan dan mencegah dari kemungkaran serta perbuatan yang baik. Kalimat yang baik bagaikan sebatang pohon yang rindang berbuah lebat, akarnya terhujam ke bumi dan akarnya menjulang ke angkasa, begitulah manfaat kalimat yang bermuatan kebenaran. Kalimat yang baik bisa dijadikan sebagai tempat berteduh bagi orang yang kepanasan dan bisa pula memberi buah yang segar bagi kesejahteraan hidup, memberikan panduan agar memandang pada angkasa yang luas untuk menyadari kebesaran Allah swt. pemilik jagad raya. Gurindam Dua Belas karya Raja Ali Haji, berkontribusi positif dan berguna bagi umat manusia khususnya umat Islam dalam menjalani kehidupan, sehingga Gurindam Dua Belas penting untuk diteliti dan dipahami maknanya dalam bentuk nilai teologi. Karena mengandung nilai teologi mendalam yang lebih mendidik dan terarah sehingga bisa diimplementasikan dalam kehidupan sehari-hari. Pembahasan Nilai Teologi (Values Theology)dalam Gurindam Dua Belas Raja Ali Haji sebagai suatu tawaran kajian dalam tulisan ini. Nilai Teologi dalam Gurindam Dua Belas memberikan pemahaman kebutuhan akan agama sebagai fitrah manusia serta dasar pijakan bagi kebahagiaan kehidupan landasan dalam memahami teologi, tingkah laku, norma dan aturan bermasyarakat. Dengan pemahaman dan pengamalan akan agama Islam serta memahami nilai-nilai teologi dalam Gurindam Dua Belas kehidupan umat manusia akan terarah pada kebenaran sehingga kehidupan terhindar dari konflik dan akan merasakan ketenangan lahir dan batin menuju kebahagiaan duniawi dan ukhrawi.
\end{abstract}

Kata Kunci: Nilai, teologi, gurindam.

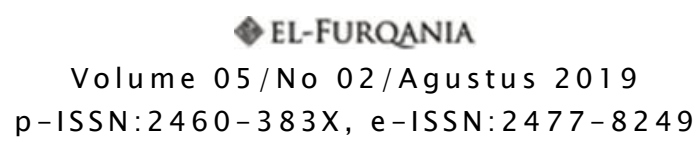


Abstract: The sentence a good is the sentence of monotheism, all sayings that call upon virtue and prevent from evil and good deeds. The sentence good is like a shady tree bearing heavy fruit, its roots are blasted into the earth and its roots soar into the sky, that is the benefit of a sentence that contains truth. A good sentence can be used as a shelter for people who are overheated and can also provide fresh fruit for the well-being of life, giving guidance to look at the vast sky to realize the greatness of Allah. owner of the universe. Gurindam Dua Belas by Raja Ali Haji, contributes positively and is useful to humanity, especially Muslims in living their lives, so that the Gurindam Dua Belas is important to examine and understand its meaning in the form of theological values. Because it contains deep theological values that are more educational and directed so that they can be implemented in everyday life. The discussion of theological values (Values Theology) in Gurindam Dua Belas Raja Ali Haji as an offer of study in this paper. The theological values in Gurindam Dua Belas provide an understanding of the need for religion as a human nature and a foundation for the happiness of basic life in understanding theology, behavior, norms and rules of society. By understanding and practicing the religion of Islam and understanding the theological values in the Gurindam Dua Belas human life will be directed to the truth so that life can avoid conflict and will feel the birth and inner calm towards worldly happiness and ukhrawi.

Keyword: Value, theology, Gurindam.

\section{Prolog}

Gurindam Dua Belas merupakan wujud bagian dari budaya tulis menulis di alam Nusantara yang berkembang pada masa silam, terbukti banyaknya naskah-naskah kuno yang terdapat di berbagai daerah di tanah air, khususnya daerah Riau. Naskah banyak berisi dokumen, informasi yang ditulis dalam bahasa Arab, Melayu, Jawa, Sunda, Aceh, Bali, Batak, dan lainnya. Naskah yang ditulis bersifat sastra, keagamaan, nasehat, nilai-nilai religius dan adat-istiadat 
dalam kemaslahatan kehidupan individu. ${ }^{1}$ Naskah bermuatan

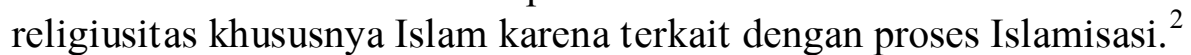

Gurindam Dua Belas karya Raja Ali Haji, berkontribusi positif dan berguna bagi umat manusia khususnya umat Islam dalam menjalani kehidupan, penting untuk diteliti dan dipahami maknanya dalam bentuk value teologi. Karena mengandung nilai teologi mendalam, mendidik sehingga bisa diimplementasikan dalam kehidupan sehari-hari. Nilai Teologi (Values Theology) dalam Gurindam Dua Belas Raja Ali Haji suatu tawaran kajian dalam tulisan ini.

\section{Nilai (Value)}

Value atau nilai didefenisikan sebagai satu ukuran, keunggulan berkaitan mutu apa saja, sebagai sasaran sosial yang dianggap pantas dan berharga untuk dicapai. ${ }^{3}$ Nilai didefenisikan dengan standar, ukuran (norma) yang digunakan untuk mengukur segala sesuatu. Gordon Allport mengatakan bahwa nilai adalah keyakinan yang membuat seseorang bertindak atas dasar pilihannya. Nilai berada pada keyakinan, keyakinan berada di tempat yang paling tinggi. Keputusan benar-salah, baik-buruk, indah-tidak indah, merupakan hasil dari proses yang mengarahkan individu pada tindakan yang sesuai dengan nilai pilihannya. ${ }^{4}$

Pertama kali yang muncul dalam jiwa ialah tujuan. Tujuan merupakan jalan yang ditempuh mendapatkan nilai dari tujuan akhir. Tujuan harus ada upaya supaya dapat menentukan tindakan. Manusia harus mempunyai tujuan akhir sebagai tujuan hidupnya. Tingkah laku menjadi baik aktualisasi akhlak, melakukan perbuatan yang membuatnya baik sebagai manusia. Kebaikan adalah sesuatu yang

\footnotetext{
1 Abdul Qadir, Sejarah Masuknya Islam di Riau, (Pekanbaru: Perpustakaan Nasional RI, 1999), hlm. 114.

${ }^{2}$ UU. Hamidy, Potensi Lembaga Pendidikan Islam di Riau, (Pekanbaru : Perpustakaan Nasional RI,1999), 114.

${ }^{3}$ J.P.Chaplin., Kamus Lengkap Psikologi, (Jakarta: Raja Grafindo Persada, 2009), hlm. 527.

${ }^{4}$ Abd. Haris, Etika Hamka Konstruksi Etika Berbasis Rasional Relegius, (Surabaya: LkiS, 2012), hlm. 30.
} 
diinginkan, diusahakan dan menjadi tujuan manusia, maka kebaikan disebut "Nilai" (value). ${ }^{5}$

Kepribadian yang berdasarkan nilai teologiterlihat dari kemampuan seseorang untuk menunjukkan ciri khas dirinya sebagai penganut agama, sikap dan perilakunya secara lahir dan batin sejalan dengan nilai-nilai pendidikan agama yang diajarkan, pola fikirnya cenderung pada keyakinan agama serta kemampuan untuk mempertahankan jati diri sebagai seorang yang beragama.

\section{Teologi Gurindam Dua Belas}

Teologi membahas ajaran-ajaran dasar dari suatu agama. Setiap orang ingin menyelami seluk beluk agamanya secara mendalam, perlu mempelajari teologi yang terdapat dalam agamanya. Mempelajari teologi akan berkontribusi pada keyakinan berdasar pada landasan kuat, tidak mudah diombang ambing oleh perputaran zaman. ${ }^{6}$ Teologi berasal dari bahasa Yunani, theos artinya Tuhan, logia diartikan dengan "kata-kata" atau wacana. maka teologi dipahami sebagai ilmu yang mempelajari segala sesuatu yang berhubungan dengan Tuhan.

Teologi Islam ialah ilmu yang membahas tentang ketuhanan, segala sesuatu yang terkait denganNya, segala sifat-Nya, Rasul dan segala sifatnya, pokok kajian ilmu teologi Islam ialah keyakinan akan eksistensi Allah swt. Teologi Islam pada awalnya berkembang sebagai metodologi: Pertama, memahami doktrin agama melalui pendekatan wahyu dan pemikiran rasional. Kedua, teologi sebuah ilmu yang membahas masalah ketuhanan segala yang berkaitan dengan-Nya. Ketiga, teologi aksiologi sebagai upaya memahamkan doktrin agama untuk mengadvokasi berbagai fenomena ketimpangan sosial. $^{7}$

Proses menjalankan keyakinan beragama dilihat pada perilaku, budi pekerti, seperti yang tertuang dalam Gurindam Dua

${ }^{5}$ Ondi Saondi \& Aris Suherman, Etika dan Profesi Guru, (Bandung: Refika Aditama, 2010), hlm. 102.

${ }^{6}$ Harun Nasution, Teologi Islam Aliran-aliran Sejarah Analisa Perbandingan, (Jakarta: UII Press, 1986), hlm. Ix.

${ }^{7}$ B.F. Drewes Mojau, Apa Itu Teologi ? (Jakarta: BPK Gunung Mulia, 2006), hlm. 17. 
Belas memiliki nilai-nilai teologis Islam yang sangat tinggi. Gurindam Dua Belas merupakan suatu karya yang sudah lama (bagian dari salah satu karya kuno yang ada di Riau) tetapi tidak musnah kandungan makna dan isi yang tertuang dalam Gurindam Dua Belas, isi naskah tersebut masih dijadikan nasehat dalam menjalani kehidupan, dan bait-bait gurindam masih dijadikan referensi oleh masyarakat dalam menyampaikan pesan-pesan teologis dalam mendidik generasi penerus dan kehidupan sosial lainnya.

Gurindam Dua Belas merupakan karya yang sulit dicari bandingannya. Keutamaan karya ini bukan semata-mata keindahan sajak dan pilihan kata dalam bentuk yang artistik, tetapi pada keindahan batinnya, kandungan pesan yang mendalam, sinar kejelasan yang murni. Gurindam Dua Belas ditulis Raja Ali Haji sebagai apresiasi yang mendalam dari al-Qur'an Surat Ibrahim [14]: 24.

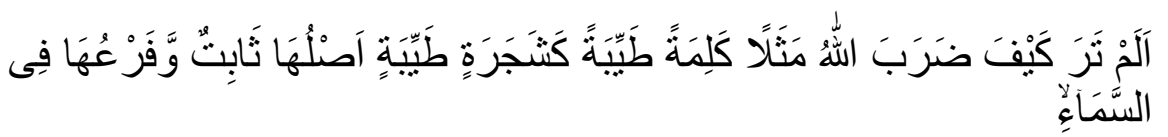

Tidakkah kamu perhatikan bagaimana Allah telah membuat perumpamaan kalimat yang baik, seperti pohon yang baik, akarnya teguh dan cabangnya (menjulang) ke langit. ${ }^{8}$

Kalimat yang baik ialah kalimat tauhid, segala ucapan yang menyeru kepada kebajikan dan mencegah dari kemungkaran. Kalimat yang baik bagaikan sebatang pohon yang rindang berbuah lebat, akarnya terhujam ke bumi dan akarnya menjulang ke angkasa, begitulah manfaat kalimat yang bermuatan kebenaran. Kalimat yang baik bisa dijadikan sebagai tempat berteduh bagi orang yang kepanasan (tertindas) dan bisa pula memberi buah yang segar (jalan yang lapang) bagi kesejahteraan hidup, panduan agar memandang pada angkasa yang luas, untuk menyadari kebesaran Allah swt. pemilik jagad raya. ${ }^{9}$ Gurindam atau sajak peribahasa terdiri dari dua baris dan saling berirama. Bait pertama mengandung satu pendirian, dugaan, penerapannya atau jawabannya dimuat pada baris kedua.

\footnotetext{
${ }^{8}$ QS. Ibrahim [14]: 24.

${ }^{9}$ UU. Hamidy, Jagad Melayu dalam Lintasan Budaya di Riau, (Pekanbaru: Bilik Kreatif Press, 2011), hlm. 142.
} 
Sifatnya ajaran budi pekerti yang dibingkai dalam peribahasa berirama sajak. ${ }^{10}$ Seperti pada pasal gurindam berikut.

\section{Pasal Pertama}

Barang siapa tiada memegang agama

Sekali-kali tiada boleh dibilang nama

Barang siapa mengenal yang empat

Maka yaitulah orang yang ma'rifat

Barang siapa mengenal Allah swt.

Suruh dan tegaknya tiada ia menyalah

Barang siapa mengenal diri

Maka telah mengenal akan Tuhan yang bahari

Barang siapa mengenal dunia

Tahulah ia barang yang terpedaya

Barang siapa mengenal akhirat

Tahulah ia dunia mudharat

\section{Nilai Teologi Gurindam Dua Belas}

Makna yang Terkandung dalam Pasal Pertama "Memberi

nasihat tentang agama (religius) "

Barang siapa tiada memegang agama

Sekali-kali tiada boleh dibilang nama. ${ }^{1}$

Setiap orang harus memiliki agama karena agama fondasi bagikehidupan, orang yang tidak memiliki agama akan buta arah dalam menjalankan hidupnya. ${ }^{12}$ Agama sebagai identitas pribadi, tanpa agama berarti tidak memiliki identitas, aturan-aturan agama tidak menyentuh kehidupannya sehingga kehidupannya tidak terarah dan tidak ada aturan. Maka agama merupakan identitas seseorang. Barang siapa mengenal yang empat Maka yaitulah orang yang ma'rifat

\footnotetext{
${ }^{10}$ J.J. De Hollander, Pedoman Bahasa dan Sastra Melayu,(Jakarta: Balai Pustaka, 1984), hlm. 253.

${ }^{11}$ Raja Ali Haji, Gurindam Dua Belas dan Sejumlah Sajak Lain, (Pekanbaru: Yayasan Pusaka Riau, 2007), hlm. 2.

${ }^{12}$ Pusat Pengajian Bahasa dan Kebudayaan Melayu, Raja Ali Haji dan Karyakaryanya,.. hlm. 33.
} 
Kesempurnaan perjalanan kehidupan, manusia mesti mengenal empat zat yang menjadikan manusia mula-mula. Empat hal tersebut adalah Allah, diri, dunia, dan akhirat. Allah adalah Tuhan yang wajib disembah. Diri merupakan bagian fisik dan psikis yang harus dikendalikan berdasar nilai teologi yang dianut. Dunia tempat hidup dan berkarya serta tempat mengaktualisasikan diri. Akhirat tempat kembali dan mempertanggungjawabkan kehidupan dunia. ${ }^{13}$

Barang siapa mengenal Allah swt.

Suruh dan tegaknya tiada ia menyalah

Orang yang mengenal Allah swt. senantiasa melakukan perintah-Nya dan menjauhi larangan-Nya. Baik secara vertikal pada sang khaliq maupun horizontal antar-sesama manusia, dengan harapan terjalin kehidupan yang harmonis.

Barang siapa mengenal diri

Maka telah mengenal akan Tuhan yang bahari

Orang yang tidak beragama akan kehilangan identitas diri dan tidak dekat dengan Allah swt. dipahami orang yang mampu mengendalikan diri berdasar perintah agama maka itulah orang yang sudah mengenal hakikat kehidupan.

Barang siapa mengenal dunia

Tahulah ia barang yang terpedaya

Mengetahui kebesaran Allah lewat manusia dalam penciptaan makhluk yang paling sempurna. Kehidupan yang hanya berorientasi pada kebahagiaan dunia saja, akan menyesal pada akhirnya, karena kehidupan dunia sesaat.

Barang siapa mengenal akhirat

Tahulah ia dunia mudharat

Memahami kehidupan akhirat, mesti menghindarkan diri dari hal yang membuat celaka.

Pengarang telah membentangkan nilai-nilai teologi Islam yaitu agama sebagai fondasi kehidupan. Values teologis dimaksud ialah Islam, fondasi dalam beramal ialah tauhid. Raja Ali Haji sebagai ulama telah membuka karyanya dengan pokok ajaran Islam sebagai fondasi dasar. Setiap manusia harus memiliki agama karena

13 Ahmad Dahlan, Sejarah Melayu, (Jakarta: Kepustakaan Populer Gramedia: 2015), hlm. 548. 
agama sangat penting bagi kehidupan, orang yang tidak mempunyai agama akan buta arah dalam menjalankan hidupnya.

Memahami Islam ialah berlandaskan nilai teologi Islam sebagaimana perasaan dan pengalaman orang-orang secara individual terhadap Tuhan, adanya ketenteraman, leganya batin orang yang merasakan dengan sungguh-sungguh bahwa Tuhan Maha Pengasih dan Penyayang dan tergolong orang yang disayang Tuhan. Hal ini dapat diteliti dan dapat dilihat pengaruhnya dalam tingkah laku. ${ }^{14}$

Esensi memahami Islam sejalan dengan nilai Islam yang memerintahkan umatnya beragama secara menyeluruh.

Firman Allah swt. Q.S. al-Baqarah [2]: 208.

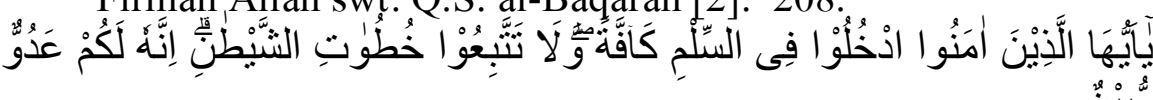

"Hai orang-orang yang beriman, masuklah kamu ke dalam Islam keseluruhan, dan janganlah kamu turut langkah-langkah setan. Sesungguhnya setan itu musuh yang nyata bagimu."

Fondasi Islam adalah tauhid atau peng-Esaan Allah swt. Tidak ada satupun perintah dalam Islam bisa dilepaskan dari Tauhid. Seluruh agama berkewajiban menyembah Tuhan, untuk melakukan perintah dan menjauhi laranganNya, kesimpulannya adalah bahwa tauhid merupakan intisari dari agama Islam, suatu tindakan tak dapat disebut bernilai Islam tanpa dilandasi kepercayaan kepada Allah swt. $^{15}$

Dalam Islam terdapat tauhid atau teologi, syariah dan akhlak, Pada dasarnya sifat asal manusia adalah baik dan manusia selalu ingin kembali kepada kebenaran sejati. Fitrah manusia mempercayai, mengakui Allah swt. sebagai Tuhannya. Adanya dorongan yang bersifat alamiah sebelum manusia diturunkan kebumi. Manusia dilengkapi berbagai potensi untuk memperoleh kesenangan, kekuasaan, kemenangan, dan sebagainya yang semuanya dapat membuat fitrah manusia dalam kegelapan berupa pertarungan sesama manusia, seperti kesombongan dan sebagainya. ${ }^{16}$

\footnotetext{
${ }^{14}$ Zakiah Darajat, Ilmu Jiwa Agama, (Jakarta: bulan Bintang, 2010), hlm. 7.

${ }^{15}$ Ibid., hlm. 79.

${ }^{16}$ Rusmin Tumanggor, Ilmu Jiwa Agama The Psychology Of Religion,...hlm. 91
} 
Implementasi nilai teologi Islam ialah ibadah yang memberi latihan rohani yang diperlukan manusia, semua ibadah yang ada dalam Islam: shalat, puasa, zakat dan haji, bertujuan agar senantiasa tidak lupa pada Allah swt. sebagai Dzat Yang Maha Suci. Rasa kesucian yang kuat dapat menjadi kontrol bagi hawa nafsu agar tidak melanggar nilai-nilai moral berlandaskan Islam. ${ }^{17}$

Setiap muslim sejatinya berfikir, bersikap maupun bertindak secara Islam. Dalam aktivitas ekonomi, sosial, politik atau aktivitas apapun, dalam rangka beribadah kepada Allah swt. dimanapun, dalam keadaan apapun, setiap muslim hendaknya mengamalkan ajaran Islam. Sejalan dengan teori Glock \& Start (Robertson 1988) menilai bahwa kepercayaan keagamaan adalah jantungnya dimensi keyakinan. $^{18}$

Dorongan beragama merupakan dorongan psikis yang mempunyai landasan alamiah dalam watak kejadian manusia. Dalam relung jiwanya manusia merasakan adanya suatu dorongan yang selalu memotivasi untuk mencari dan memikirkan Sang pencipta. Alam semesta dan seisinya meminta pertolongan pada Allah swt. setiap kali tertimpa musibah dan malapetaka. Dalam perlindungan Allah swt. Makhluk merasa tenang dan tenteram. Jalan yang ditempuhnya dalam menyembah Tuhan berbeda-beda sesuai dengan tingkat pemikiran dan perkembangan budaya yang ada dimasyarakat. ${ }^{19}$

Pendidikan jasmani manusia harus disempurnakan dengan pendidikan rohani karena keduanya saling membutuhkan. Pengembangan daya jasmani seseorang tanpa dilengkapi pengembangan daya rohani akan membuat hidup berat sebelah dan kehilangan keseimbangan. Roh yang ada dalam diri manusia harus mendapat latihan, sebagaimana badan manusia juga mendapat

\footnotetext{
${ }^{17}$ Ibid., hlm. 31.

${ }^{18}$ Djamaludin Ancok dan Fuat Nashori Suroso, Psikologi Islami Solusi Islam Atas Peroblem-problem Psikologi, (Yogyakarta: Pustaka Pelajar, 2011), hlm. 79.

${ }^{19}$ Utsman Najati, Alqur'an dan Ilmu Jiwa, (Bandung: Pustaka Setia, 2004), hlm. 40 .
} 
latihan. Melaksanakan aturan Allah swt. Dengan cara mematuhi aturan Allah menjauhkan diri dari semua hal yang dilarang. ${ }^{20}$

Dasar dari seluruh teologi adalah iman kepada Allah swt. merupakan satu kewajiban untuk mengesakan Allah swt. melepaskan diri dari kesyirikan, kotoran, kepalsuan, kezhaliman dan kesesatan yang nyata. Maka siapa yang tidak mengenal hakikat Allah swt. Ia belum mengenal dirinya sebagai manusia yang diciptakan. ${ }^{21}$ Mengetahui kebesaran Allah lewat manusia, makhluk ciptaanNya yang paling sempurna. Manusia yang berorientasi pada kebahagiaan atau hanya mencari kebahagiaan di dunia saja, sebenarnya tertipu dan tidak menyadari bahwa di dunia hanya sesaat. Manusia diutus ke dunia sebagai tamu dan petugas serta diberi berbagai potensi dan kesiapan yang penting, dengan demikian kepadanya diembankan tugas-tugas mulia. Agar manusia bisa menjalankan pekerjaannya, mengusahakan tujuan-tujuan dan tugastugas yang besar, dalam diri manusia diberi motivasi dan ancaman agar menjalankan perintah Islam. ${ }^{22}$

Segala hal yang berkaitan tentang tauhid atau pada dasarnya manusia beragama. Maka dorongan mengimplementasikan nilai-nilai teologi Islam menuntut untuk dipenuhi, sehingga pribadi mendapat kepuasan dan ketenangan. Dorongan beragama merupakan kebutuhan insan dari berbagai faktor yang bersumber dari rasa keagamaan. Tingkah laku keagamaan dipengaruhi oleh pengalaman keagamaan, struktur kepribadian, serta unsur kejiwaan lainnya, sejalan dengan kebutuhan manusia dan berkembang selaras dengan tingkat usia. ${ }^{23}$

Raja Ali Haji membentangkan nilai-nilai teologi berdasarkan Islam dan membuka karyanya dalam Gurindam Dua Belas dengan pokok ajaran Islam yang paling mendasar yaitu tauhid. Memposisikan nilai teologi berlandaskan agama Islam sebagai sesuatu yang fundamental bagi manusia. Menurut Raja Ali Haji, orang yang tidak beragama seolah-olah tidak memiliki identitas diri.

\footnotetext{
${ }^{20}$ Harun Nasution, Islam di Tinjau dari Berbagai Aspeknya, (Jakarta: UI Press, 2001), hlm. 30.

${ }^{21}$ Djamaludin Ancok \&Fuat Nashori, Psikologi Islami...,. hlm.80.

${ }^{22}$ Budi' uzzaman Sa'id Nursi, Iman Kunci Kesempurnaan, (Jakarta: Rabbani Press, 1988), hlm.58.

${ }^{23}$ Djalaludin, Psikologi Agama... hlm. 90.
} 
Semakin manusia mengenal Allah swt, maka semakin takut padaNya. Kehidupan manusia yang berorientasi pada kebahagiaan di dunia sebenarnya tertipu karena tidak menyadari kalau dunia fana sebenarnya merugikan.

Esensi teologi Islam dasarnya ialah agama Islam, dasar implementasinya ialah memahami dan mengamalkan nilai-nilai teologi Islam dalam kehidupan, dan orientasi teologi Islam ialah mendekatkan diri pada Allah swt. Fitrah manusia beragama, agama bisa dipahami melalui pendidikan, landasannya ialah aqidah, cara beribadah melalui syariah dan aktualisasinya melalui akhlak. Pembahasan pasal pertama membahas agama sebagai fitrah yang dikaitkan dengan aqidah sekaligus sebagai kebutuhan manusia. Proses pendidikan berjalan dengan baik pada anak bila kebutuhan dasarnya terpenuhi baik dari aspek fisiologis maupun psikologis. Pemahaman agama harus didasarkan pada keimanan pada Allah swt. sehingga muncul motivasi untuk memikirkan Sang Pencipta, sehingga berkeinginan untuk menghambakan diri pada-Nya tentu saja seorang anak akan berfikir bagaimana cara beribadah pada Allah swt. Melalui proses pendidikan, pengalaman dan latihan seseorang, aktualisasinya ada pada akhlak dengan melakukan printah Allah swt. dan menjauhi larangan-Nya, ketika seseorang tertimpa musibah, bencana, atau berada pada level kegelisahan maka ia akan meminta pertolongan pada Allah swt. sehingga mentalnya menjadi sehat dan melahirkan beberapa sifat dan tingkah laku positif seperti perasaan tenang, fikiran sehat, tingkah laku baik, dan fisik menjadi sehat.

Teologi merupakan dorongan psikis yang mempunyai landasan alamiah dalam watak kejadian manusia, relung jiwa manusia merasakan adanya suatu motivasi untuk mencari dan memikirkan Sang Penciptanya dan meminta pertolongan pada-Nya setiap kali tertimpa musibah dan malapetaka. Dalam perlindunganNya akan merasa tenang dan tenteram, hal seperti ini bisa diperhatikan pada tingkah laku manusia dalam berbagai aspek

\footnotetext{
${ }^{24}$ Pendidikan yang sangat dibutuhkan manusia ada dua yaitu Esensi Islam adalah tauhid atau pengesaan Allah swt. tindakan yang menegaskan Allah sebagai Yang Maha Esa pencipta yang mutlak dan transenden, penguasa segala yang ada. Tidak ada satupun perintah dalam Islam yang bisa dilepaskan dari Tauhid. Djamaludin... Ibid., hlm. 79.
} 
kehidupan masyarakat. Konsepsi manusia dalam berbagai masyarakat sepanjang sejarah jalan yang ditempuhnya menyembah Allah swt., sesuai tingkat pemikiran dan perkembangan budayanya. ${ }^{25}$

Rohani tenteram kalau sudah beriman dan selalu mengingat Allah swt., beriman dan mengingat-Nya hanya dapat dilakukan dengan beragama. Kehidupan dunia modern sekarang adalah kehidupan dunia yang tidak tenteram, Madame Bovazaf Qiqinoout dalam bukunya Good Luck Healty, mengatakan bahwa noda besar kehidupan zaman modern adalah kegelisahan. Kegelisahan merupakan gangguan utama umat manusia. Kegelisahan hanya dapat diobati melalui pemahaman agama. Menurut agamawan dan ilmuwan ketenteraman rohani hanya akan terwujud melalui pengamalan ajaran agama (Islam). ${ }^{26}$

Firman Allah QS. al-Ra'du [13]: 28.

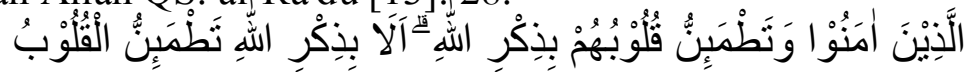

Orang-orang yang beriman dan hati mereka manjadi tenteram dengan mengingat Allah. Ingatlah, Hanya dengan mengingati Allah-lah hati menjadi tenteram. ${ }^{27}$

Makna yang termaktub pada Gurindam Dua Belas, kental dengan nilai teologi Islam, gurindam berisi wejangan yang berguna bagi masyarakat, khususnya masyarakat tempat Raja Ali Haji tinggal, yaitu masyarakat Melayu, dominannya pengaruh Islam dalam kehidupan masyarakat Melayu sebagai dampak lancarnya proses Islamisasi di wilayah tersebut, khususnya Kepulauan Riau. Gurindam Dua Belas menyerap nilai-nilai Islam yang tinggi kemudian memancarkannya dalam bentuk gurindam, perkataan yang bersajak pada akhir pasangannya; pertama syarat yang kedua jawab. Dengan rendah hati pengarang piawai berpesan bahwa gurindam ini boleh diambil faedah sedikit-sedikit. ${ }^{28}$

\footnotetext{
${ }^{25}$ Utsman Najati, Al-Qur'an dan Ilmu Jiwa (Bandung: Pustaka Setia, 2004), hlm. 40.

${ }^{26}$ Syahminan Zaini, Pedoman Aqidah Islam (Jakarta: Pustaka Darul Ilmi, 2006), hlm. 12.

${ }^{27}$ QS. al-Ra'du [13]: 28.

${ }^{28}$ Maksudnya memahami, dan merenungkan pesan yang terdapat dalam Gurindam Dua Belas serta mengamalkannya dalam kehidupan sehari-hari. UU. Hamidy Jagad Melayu Dalam Lintasan Sejarah, (Pekanbaru: Bilik Kreatif Press, 2011), hlm. 142.
} 
Kehidupan masyarakat modern mudah dipengaruhi aspek gaya hidup borjuis (bersifat material), budaya individual (kebebasan personal) dari Barat, selaras melupakan kehidupan yang hakiki, sehingga budaya timur seakan sudah menyatu dengan budaya Barat. Mengedepankan kehidupan serba materi sesungguhnya kebahagiaan dan hakikat kehidupan akan lebih dirasakan. Maka kebahagiaan sesungguhnya tidak bergantung pada materi tetapi bagaimana suasana spritualitas dalam memahami dan mendekatkan diri pada Allah swt. seperti yang tertuang dalam naskah Gurindam Dua Belas karya Raja Ali Haji.

Problematika kehidupan perlu diminimalisir, disikapi dengan bijak dengan cara yang baik, menjalani kehidupan perlu ketenangan, keseimbangan sosial, ketenteraman, berdasar ilmu pengetahuan dan ketaatan pada agama yang dianut, perlu sifat ramah-tamah, tolongmenolong, saling memahami antara seseorang dengan orang lain, menghormati, empaty, honesty, baik dalam keluarga maupun di masyarakat, terwujud kehidupan masyarakat yang tertib dan tenteram, terhindar dari pertengkaran, dan permusuhan, sehingga bahagia dalam menjalani kehidupan

Nilai teologi dalam naskah Gurindam Dua Belas mengarahkan pada terwujudnya kebahagiaan, ketenangan. Hakikat kebahagiaan bukan pada banyak harta atau tidak memiliki harta seperti yang dipahami oleh kaum sekuler, materialis dan hedonis. Kebahagiaan di dunia bisa diraih jika berpegang teguh pada ajaran al-Qur'an dan Sunnah Rasulullah saw., mengingat kehidupan dunia singkat, maka tidak layak mengabaikan kehidupan yang abadi.

\footnotetext{
${ }^{29}$ Hidayat Syah, Islam dan Tamaddun Melayu, (Pekanbaru: LPPM STAI Diniyah Pekanbaru, 2011), hlm. 7.
} 


\section{Peta Konsep Pasal Pertama}

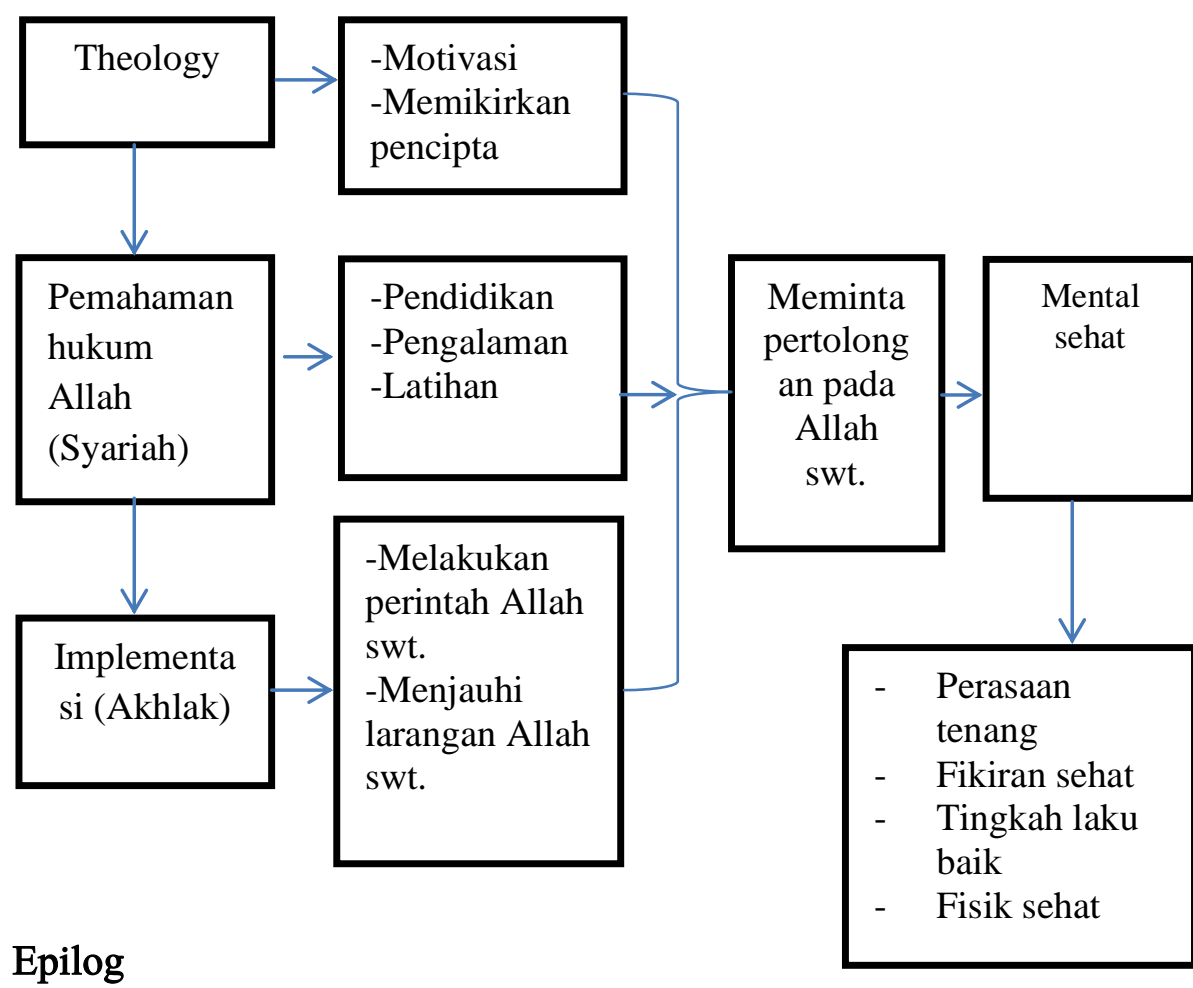

Nilai Teologi dalam Gurindam Dua Belas memberikan pemahaman kebutuhan agama sebagai fitrah manusia serta dasar pijakan bagi kebahagiaan kehidupan landasan dalam memahami teologi, tingkah laku, norma dan aturan bermasyarakat. Dengan pemahaman agama Islam serta mengamalkan nilai-nilai teologi dalam Gurindam Dua Belas kehidupan umat manusia akan terarah pada kebenaran sehingga kehidupan terhindar dari konflik dan akan merasakan ketenangan lahir dan batin menuju kebahagiaan duniawi dan ukhrawi. 


\section{Daftar Kepustaka}

Ali, Raja Haji, Gurindam Dua Belas dan Sejumlah Sajak Lain, Pekanbaru: Yayasan Pusaka Riau, 2007.

Ancok, Djamaludin dan Fuat Nashori Suroso, Psikologi Islami Solusi Islam Atas Peroblem-problem Psikologi, Yogyakarta: Pustaka Pelajar, 2011.

Chaplin, J.P. Kamus Lengkap Psikologi, Jakarta: Raja Grafindo Persada, 2009.

Dahlan, Ahmad, Sejarah Melayu, Jakarta: Kepustakaan Populer Gramedia: 2015.

Darajat, Zakiah, Ilmu Jiwa Agama, Jakarta: Bulan Bintang, 2010.

Drewes, B.F. Mojau, Apa Itu Teologi? Jakarta: BPK Gunung Mulia, 2006.

Hamidy, UU. Potensi Lembaga Pendidikan Islam di Riau, Pekanbaru: Perpustakaan Nasional RI,1999.

Hamidy, UU., Jagad Melayu dalam Lintasan Budaya di Riau, Pekanbaru: Bilik Kreatif Press, 2011.

Haris, Abd. Etika Hamka Konstruksi Etika Berbasis Rasional Relegius, Surabaya: LkiS, 2012.

Hollander, J.J. De, Pedoman Bahasa dan Sastra Melayu,Jakarta: Balai Pustaka, 1984.

Jalaludin, Psikologi Agama Memahami Perilaku Keagamaan dengan Mengaplikasikan Prinsip-prinsip Psikologi, Jakarta: Raja Grafindo Persada, 2005.

Najati, Utsman, Alqur'an dan Ilmu Jiwa, Bandung: Pustaka Setia, 2004.

Nasution, Harun, Islam Ditinjua dari Berbagai Aspek, Jakarta: UI Press, 2001.

Pusat Pengajian Bahasa dan Kebudayaan Melayu, Raja Ali Haji dan Karya-karyanya, tt.

Qadir, Abdul. Sejarah Masuknya Islam di Riau, Pekanbaru: Perpustakaan Nasional RI, 1999.

Sa'id, Budi'uzzaman Nursi, Iman Kunci Kesempurnaan, Jakarta: Rabbani Press, 1988.

Zaini, Syahminan, Pedoman Aqidah Islam, Jakarta: Pustaka Darul Ilmi, 2006. 